\title{
A ÁREA CALMA NA REGIÃO CENTRAL DE CURITIBA Possibilidades de estruturação e viabilização por meio do Desenho Urbano
}

\section{THE ÁREA CALMA IN THE CENTRAL REGION OF CURITIBA Possibilities of structuring and viabilization through the Urban Design}

\author{
A. Andressa Amorim Olivieri \\ Arquitetura e Urbanismo; Universidade Federal do Paraná (UFPR), Brasil \\ andressaaolivieri@gmail.com
}

\begin{abstract}
RESUMO
Este artigo foi desenvolvido a partir de uma Monografia e um Trabalho Final de Graduação, apresentados como conclusão do Curso de Arquitetura e Urbanismo da Universidade Federal do Paraná (UFPR). Tem o objetivo de estudar a Área Calma de Curitiba, de modo a investigar a realidade e questionar a definição e a dinâmica atuais, ligadas à redução do limite de velocidade na região central da cidade. Considerando a esfera teórica do Desenho Urbano, busca-se reconhecer como esse campo do conhecimento pode contribuir para a viabilização e a melhor estruturação da área. A metodologia envolve a pesquisa da realidade, incluindo a configuração atual, a percepção das pessoas por meio de um questionário, o estabelecimento de escalas e o reconhecimento de problemáticas. Como resultados, essa última ação possibilitou a criação de recomendações, espaciais e de aplicação de instrumentos urbanísticos, que solucionassem as questões, relacionadas a mobilidade, vitalidade e qualidade do espaço urbano.
\end{abstract}

Palavras-chave: Desenho Urbano, Área Calma, Curitiba.

Linha de Investigação: 1: Cidade e projeto. Tópico: Projeto urbano e espaço público.

\begin{abstract}
This article was developed from a Monography and a Final Graduation Project presented as the conclusion of the Architecture and Urbanism Course from the Federal University of Paraná (UFPR). It has the objective of studying the Área Calma of Curitiba, in a way of investigating the reality and questioning its current definition and dynamic, connected to the reduction of the speed limit in the central region of the city. Considering the Urban Design theoretical sphere, it is sought to recognize in which way this knowledge field can contribute to the viabilization and the better structuring of the area. The methodology involves the reality search, including the current configuration, the people's perception through a questionnaire, the establishment of scales and the recognition of problems. As results, this last action enabled the creation of recommendations, spatial and of applicating urban planning instruments, that would solve the issues, related to mobility, vitality and quality of the urban space.
\end{abstract}

Keywords: Urban Design, Área Calma, Curitiba.

Research line: 1: City and project. Topic: Urban project and public space. 


\section{SÃO PAULO15 $\sim 17 \cdot$ LISBOA $25 \sim 26$ JUN 2020

\section{INTRODUÇÃO}

A região central do Município de Curitiba apresenta, desde 2015, uma área estabelecida por um limite de velocidade de $40 \mathrm{~km} / \mathrm{h}$, que inclui 140 quarteirões e dois bairros, sendo eles o Centro e o São Francisco. O discurso defendido pelo Decreto de Implantação da Área Calma, de 2015, foi de uma tentativa de humanização dos espaços públicos, estando apoiado em algumas intenções. Entre essas, estão diminuir os índices de acidentes de trânsito, melhorar a convivência entre diferentes modais, favorecer a qualidade de vida e aumentar a acessibilidade e a segurança viária (Curitiba, 2015a).

Dessa forma, o projeto surgiu em função da grande quantidade de mortes causadas por acidentes de trânsito, principalmente em locais com muito tráfego como a região central, mas também, se relaciona com tendências internacionais, que promovem a diminuição do limite de velocidade nas áreas centrais, com o intuito de desestimular o uso do carro e priorizar o pedestre (Olivieri, 2019). Ligado a isso, também, estão questões associadas ao espaço e ao desenho, presentes no Estudo de Viabilidade realizado pelo IPPUC (Instituto de Pesquisa e Planejamento Urbano de Curitiba) em 2014, que teve o objetivo de investigar a área e gerar propostas para o projeto que seria desenvolvido posteriormente. Porém, essas foram pouco detalhadas, o que prejudicou a aplicação delas, resultando na criação de uma área delimitada pela SETRAN (Secretaria Municipal de Trânsito) sem a presença de um projeto e, portanto, sem análise, diagnóstico e proposições espaciais.

Então, a principal hipótese, baseada na observação da área, é a de que, atualmente, esse local é definido somente por um limite de velocidade, sem uma atenção específica para o espaço urbano em que está inserido. Assim, questiona-se se essa estratégia para a diminuição da velocidade é suficiente para definir a área e fazer com que ela funcione de maneira a reforçar o convívio social e promover o uso de diferentes modais, sendo entendida e respeitada por todos os usuários.

Para compreender o contexto urbano apontado e o desenvolvimento deste artigo, é necessário definir o conceito de Desenho Urbano e reconhecer a importância desse assunto. Mesmo antes de existir como campo disciplinar, as cidades apresentavam formas urbanas, decorrentes de diferentes processos de ocupação ao longo da história (Lamas, 1993). Com o passar das décadas, as cidades foram se tornando mais complexas, ao mesmo tempo em que surgiram teorias urbanísticas, com entendimentos próprios em relação ao contexto urbano. Alguns exemplos são o conceito de cidade-jardim, criado por Ebenezer Howard, e os planos higienistas de Georges-Eugène Haussmann em Paris e de lldefonso Cerdá em Barcelona (Hall, 2005). Entre o final do século XIX, e a Primeira Guerra Mundial, o urbanismo se tornou uma disciplina independente, procurando gerar respostas para os problemas das cidades na época (Lamas, 1993).

A partir da década de 1960, o Desenho Urbano começou a se estabelecer como campo de conhecimento, em função de críticas relacionadas à falta de qualidade do espaço urbano, envolvendo, também, uma rejeição ao Movimento Moderno. O reconhecimento de problemas, como a deterioração de áreas centrais, a falta de atenção para a complexidade urbana e o impacto ambiental e social de grandes empreendimentos, tornou perceptível a necessidade de mudança no desenvolvimento das cidades. Tendo em vista essas questões problemáticas do espaço público, identificou-se uma lacuna entre o Planejamento Urbano e a Arquitetura, o que criou uma demanda urbana antes não existente. Essa, então, foi atendida pelo Desenho Urbano, que promoveu novas formas para analisar e atuar na cidade, tornando-se mais relevante e se consolidando como campo disciplinar, inclusive com a criação de cursos de graduação nessa área (Del Rio, 1990). 


\section{SÃOPAULO15 $17 \cdot$ LISBOA $25 \sim 26$ JUN 2020}

\section{ANÁLISE DA REALIDADE}

\subsection{Contexto e dados da Área Calma}

A Área Calma de Curitiba (Fig. 1) foi implantada em 16 de novembro de 2015, englobando, aproximadamente, 140 quarteirões e com perímetro demarcado pelas ruas Inácio Lustosa, Padre Agostinho, Visconde de Nácar, André de Barros, Nilo Cairo, Mariano Torres, Luiz Leão e um trecho da Avenida João Gualberto. A maior parte está localizada dentro do Centro, mas também, possui uma parte no bairro São Francisco, apresentando zoneamentos de Zona Central, Setor Histórico e Zona Residencial. Em relação aos usos, a área apresenta habitações, com aproximadamente 21 mil moradores, além da predominância de comércios e serviços. Também conta com uma grande quantidade de praças, sendo que muitas estão associadas à função de transporte coletivo, e de equipamentos públicos, incluindo os educacionais e culturais (Curitiba, 2016, 2015b).
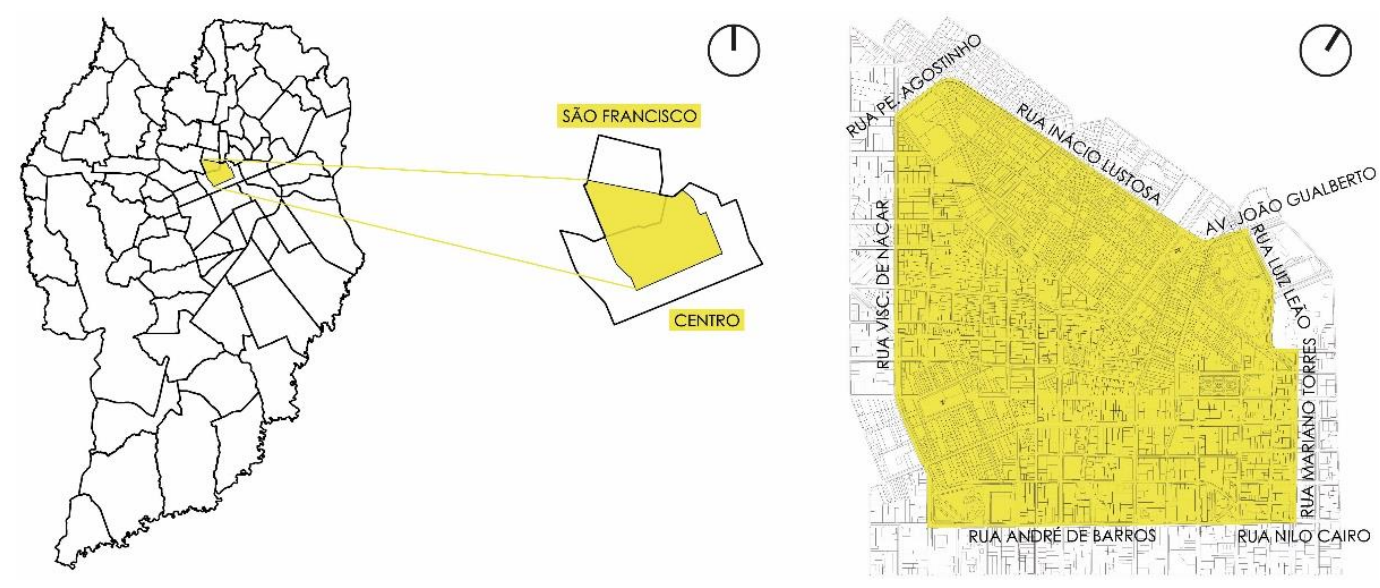

Fig. 1 - Mapa de localização e de limite da Área Calma. Fonte: Elaboração própria, 2019

A proposta foi apoiada por um discurso de humanização dos espaços públicos, com a intenção de diminuir os deslocamentos por transporte individual e priorizar os meios não motorizados. Isso está relacionado com a presença de várias ruas de uso preferencial ou exclusivo de pedestres na área, com acesso de veículos reduzido ou suprimido, como o Calçadão da Rua XV de Novembro, a Travessa Oliveira Bello, a Rua Senador Alencar Guimarães, a Rua Dr. Claudino dos Santos - Largo da Ordem -, um trecho da Rua Mateus Leme e outro da Rua Saldanha Marinho. Também se buscou oferecer maior segurança para as pessoas que circulam pelo local, cerca de 700 mil por dia, visando a redução do número de acidentes (Curitiba, 2015b).

O Decreto ํo 871/2015, que trata da implantação da Área Calma no Município de Curitiba, explica as necessidades existentes na área central que levaram à ideia desse projeto. Assim, as intenções presentes eram diminuir os índices de acidentes de trânsito, estimular um melhor convívio entre pedestres, ciclistas e motoristas, favorecer a qualidade de vida das pessoas que utilizam o local e aumentar a acessibilidade e a segurança viária, considerando que a região central apresenta grande fluxo de usuários de modais mais vulneráveis, como pedestres e ciclistas (Curitiba, 2015a). 


\section{SÃO PAULO15 17 LISBOA $25 \sim 26$ JUN 2020

Para a elaboração do projeto da Área Calma, foi realizado um Estudo de Viabilidade pelo Instituto de Pesquisa e Planejamento Urbano de Curitiba (IPPUC), em 2014, com o objetivo de analisar o local e determinar diretrizes e propostas para a qualificação do recorte. A principal intenção demonstrada pelo estudo foi a de recuperar a escala humana, envolvendo aspectos de requalificação paisagística, estruturação física, mobilidade, desenvolvimento socioeconômico e segurança. A partir da análise de diversas características da área, foram definidas algumas propostas que deveriam orientar as intervenções a serem realizadas na Área Calma, como a expansão dos espaços destinados a pedestres, a inserção de faixas exclusivas de transporte coletivo, a constituição de um sistema cicloviário, a criação de parklets, a implantação de nova iluminação pública, a definição de uma identidade visual própria e a destinação de alguns espaços públicos para atividades e eventos culturais (IPPUC, 2014).

Porém, apesar da tentativa de expor as propostas que serviriam como base para a estruturação da Área Calma, observa-se que essas não foram muito explicadas e detalhadas, gerando dúvidas sobre como seriam aplicadas. Em função disso, acabaram não sendo colocadas em prática, o que reduziu a ideia de implantação de uma área de tráfego lento a somente uma sinalização e uma diminuição do limite de velocidade, possivelmente prejudicando a qualidade espacial que poderia existir no local, se as outras ações tivessem sido adotadas.

\subsection{Levantamento}

Com o intuito de compreender as características espaciais do recorte e complementar a análise anterior, foi realizado um levantamento por meio de seleção e mapeamento de alguns aspectos considerados de maior importância para a área de estudo. Os aspectos escolhidos foram a morfologia, a regularidade das quadras, o gabarito, a existência de espaços livres, os fluxos de modais, o uso do solo e os cheios e vazios.

A morfologia da área foi analisada a partir da observação de elementos como formato das quadras, dimensões e disposição de lotes e desenho das ruas. Com isso, o recorte foi dividido em algumas partes, considerando que cada uma apresenta características próprias em relação ao caráter morfológico. Através dessa divisão, foram reconhecidos três aspectos importantes para a área.

O primeiro deles foi a regularidade das quadras, que indicou a existência de alguns locais específicos com quadras muito regulares ou irregulares, mas uma predominância de quadras moderadamente regulares. $O$ segundo aspecto foi o gabarito, que revelou uma maior presença de construções com altura média ou gabarito variável. O terceiro e último aspecto corresponde aos espaços livres, que possibilitou reconhecer as regiões que apresentam, ou não, esses espaços. Tais observações, ligadas à divisão morfológica, contribuem para melhorar a análise a respeito das características físicas desses locais.

Em relação aos modais, notou-se um contraste entre a região do bairro Centro, com alto fluxo de pedestres, mas ainda, com a presença de outros modais, e a do bairro São Francisco, com uma predominância de veículos motorizados individuais. $\mathrm{O}$ uso do solo revelou a mesma diferença entre bairros, onde o Centro apresenta mais usos comercias e mistos, enquanto o São Francisco possui mais uso residencial. Já outros, como serviços, institucional e estacionamento, estão presentes de forma significativa em ambos. Por último, os cheios e vazios evidenciaram uma intensa ocupação do solo no Centro, principalmente no Centro Histórico, e uma menor ocupação, conforme há um distanciamento dessa região. Também se destacaram os vazios que resultam das praças e de outros espaços livres na área. 


\section{XII \\ Seminário Internacional de \\ Seminario Internacional de Investigação em Urbanismo

O levantamento revelou as expressivas diferenças internas na Área Calma, em relação a todos os aspectos estudados. Com isso, foi gerado um mapa síntese (Fig. 2) que apresenta uma divisão em sete regiões, definidas por meio da sobreposição de alguns aspectos, como uso do solo, taxa de ocupação e fluxo de modais. Essas regiões podem ser entendidas como unidades de paisagem, por representarem espaços urbanos que se caracterizam pelos aspectos citados e formam imagens específicas de cada uma. Além disso, elas estabelecem relações diversas entre si, como as de continuidade, diferenças, interrupção e fluxo de pessoas.

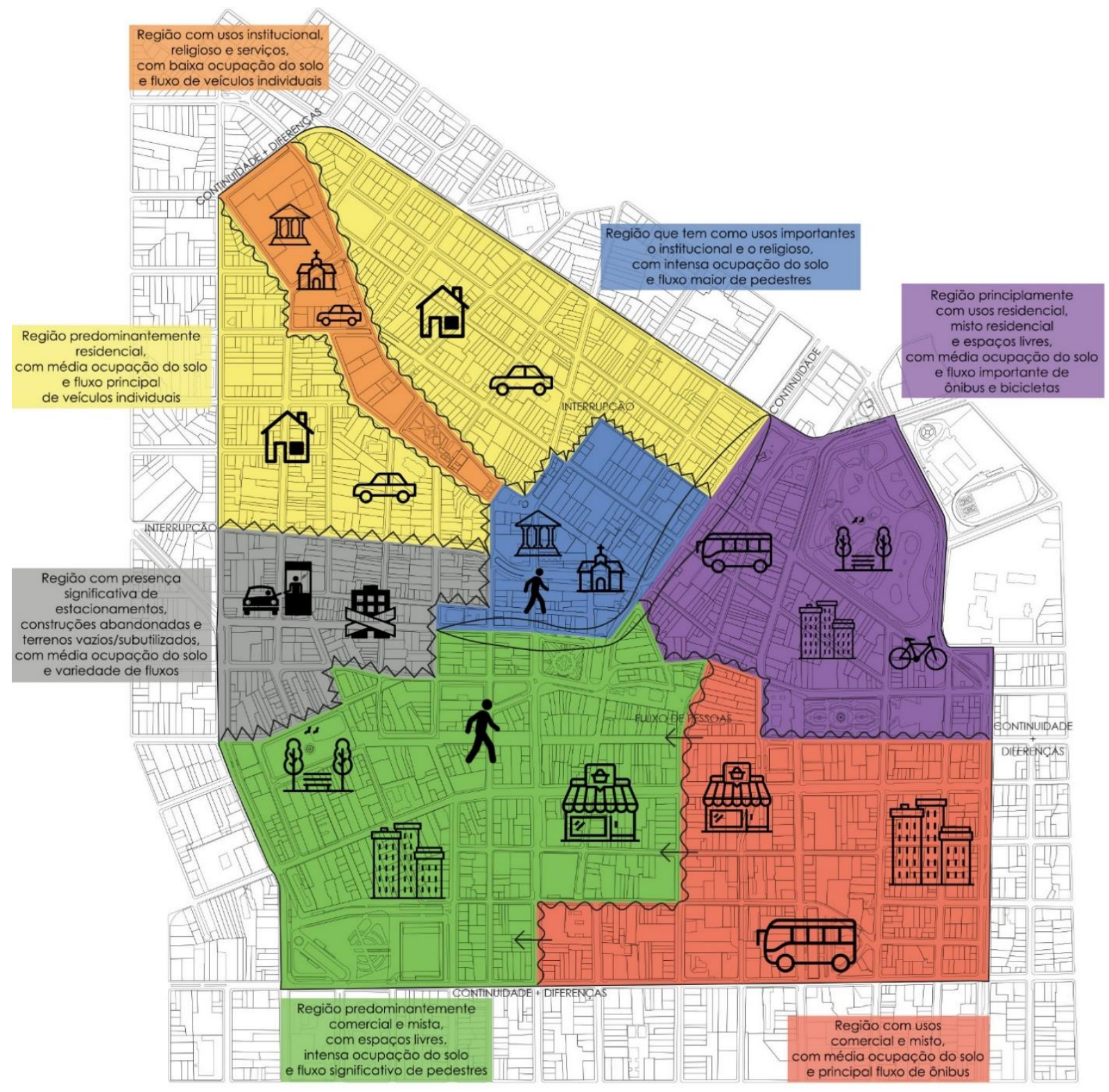

Fig. 2 - Mapa síntese do levantamento. Fonte: Elaboração própria, 2019. 


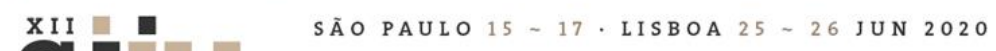

\subsection{Questionário}

Outra etapa da pesquisa foi a aplicação de um questionário, desenvolvido e divulgado a partir da plataforma Google Forms, com o objetivo de reconhecer a percepção que as pessoas têm a respeito da Área Calma. Foram obtidas 113 respostas e o questionário consistiu em 12 perguntas objetivas, sendo duas de múltipla escolha, além da possibilidade de escrever um comentário sobre o assunto no final. As perguntas envolveram, inicialmente, a relação da pessoa com o Centro de Curitiba, para, então, se direcionarem para a compreensão do conceito e das características da Área Calma, procurando entender percepções sobre a situação atual e como essa poderia ser modificada.

A primeira pergunta (Fig. 3) diz respeito à frequência com a qual os entrevistados utilizam o Centro de Curitiba, o que teve como resposta $72,6 \%$ de pessoas que vão constantemente ao bairro. Em relação ao entendimento do Centro como diferente de outras regiões (Fig. 3), a maioria (89,4\%) reconhece essa característica. Ainda sobre a área central, $95,6 \%$ dos entrevistados conseguem identificar nesse local pontos de referência ou de importância para a cidade (Fig. 3). Essas informações demonstram e confirmam a alta utilização e o caráter de relevância que a região central possui, pelo ponto de vista dos habitantes.

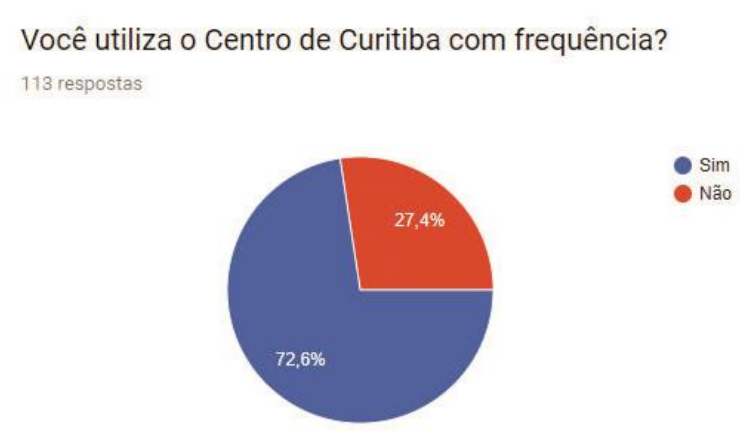

Quando você está no Centro, reconhece ele como diferente das outras regiões da cidade?

113 respostas

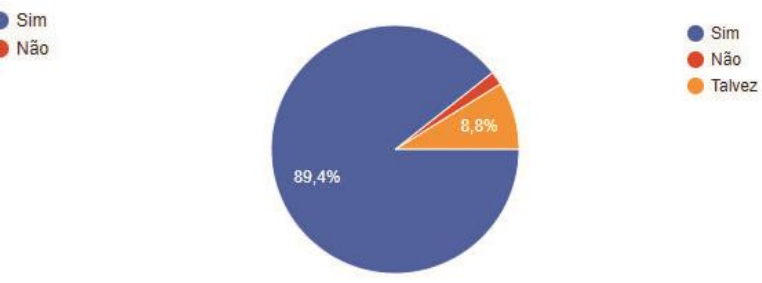

No Centro, você consegue identificar alguns pontos de referência ou de importância para a cidade?

113 respostas

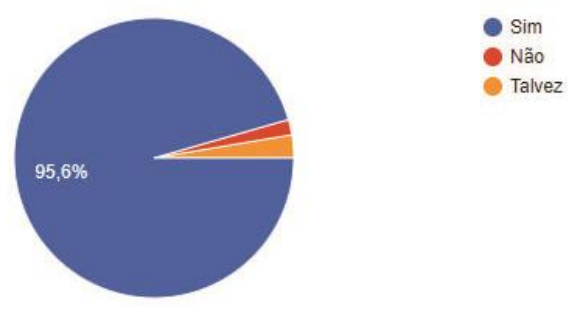

Fig. 3 - Resultado das perguntas 1, 2 e 3. Fonte: Gerada pelo Google Forms a partir de questionário de elaboração própria, 2019

Mais especificamente sobre a Área Calma, $91,2 \%$ das pessoas conhecem o projeto implantado (Fig. 4) e $45,1 \%$ dizem saber reconhecer quando estão dentro do perímetro da área (Fig. 4), mas 33,6\% não têm certeza e $21,2 \%$ não possuem essa percepção. A maioria (86,7\%) também acredita saber o objetivo da 


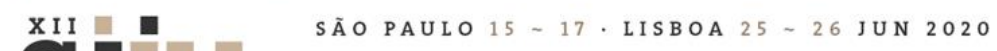

Seminário Internacional de Investigação em Urbanismo
Seminario Internacional de Investigación en Urbanismo

região (Fig. 4), porém, 45,1\% têm dúvidas se o funcionamento é adequado e 31,9\% consideram que esse não está em boas condições (Fig. 4). A respeito dos meios de transporte mais utilizados (Fig. 5) para deslocamento na área, com a possibilidade de escolher mais de uma opção, foram apontados o carro em primeiro lugar, com $77,9 \%$, a locomoção a pé em segundo, com $62,8 \%$, e o ônibus em terceiro, com $49,6 \%$, além de outros modais menos citados, como bicicleta, moto e patinete. A sensação de segurança em relação ao trânsito dentro da área (Fig. 6), quando comparada com outros pontos da cidade, não é percebida como maior por $40,7 \%$ dos entrevistados, sendo que $31 \%$ apresenta incerteza sobre essa questão. Já sobre as condições da sinalização do local (Fig. 6), a maioria (76,1\%) concorda que essa não é satisfatória.

Você conhece o projeto da Área Calma implantado no Centro? Você sabe reconhecer quando está dentro do perímetro da Área Calma? 113 respostas

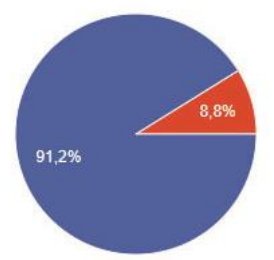

Você sabe qual é o objetivo dela? 113 respostas
- sim Não

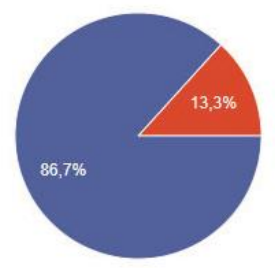

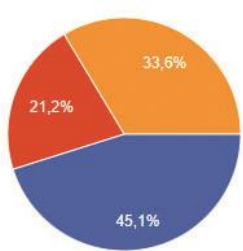

Você acha que ela funciona bem? 113 respostas
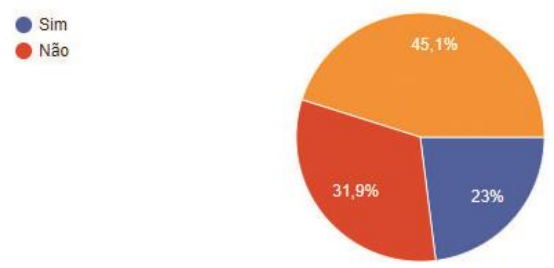

Sim

Talvez

Fig. 4 - Resultado das perguntas 4, 5, 6 e 7. Fonte: Gerada pelo Google Forms a partir de questionário de elaboração própria, 2019 Quais meios de transporte você utiliza para se deslocar dentro dela? 113 respostas

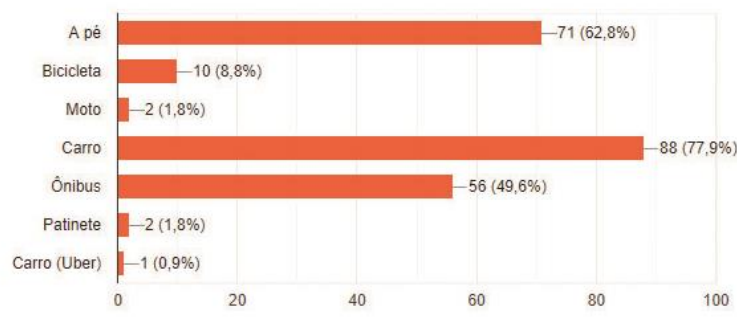

Fig. 5 - Resultado da pergunta 8. Fonte: Gerada pelo Google Forms a partir de questionário de elaboração própria, 2019 


\section{SÃO PAULO15 17 LISBOA $25 \sim 26$ JUN 2020}

Seminário Internacional de Investigação em Urbanismo

Seminario Internacional de Investigación en Urbanismo

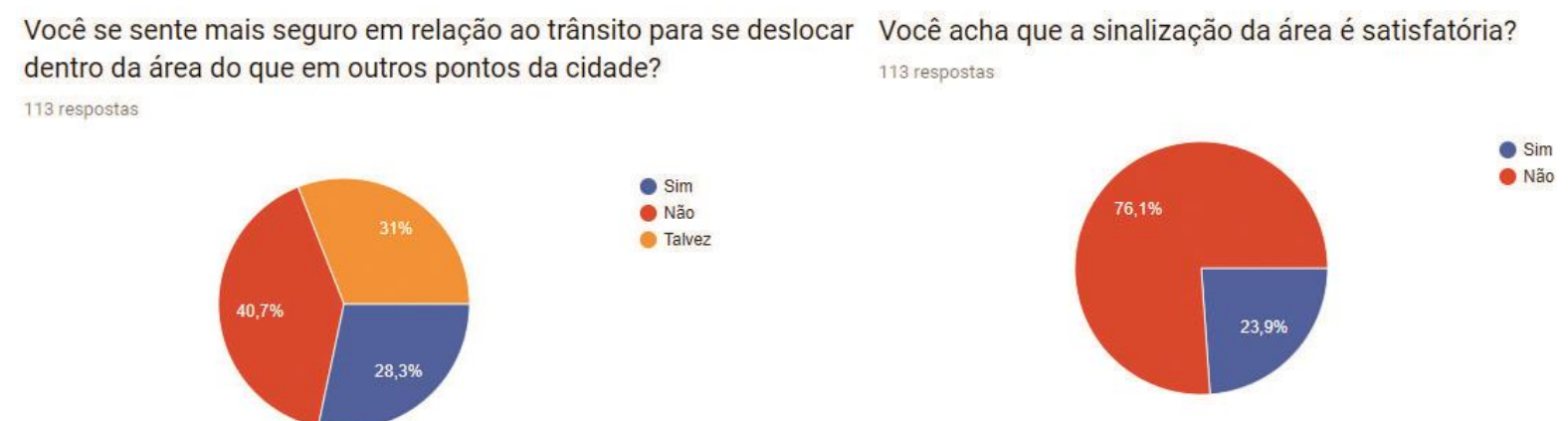

Fig. 6 - Resultado das perguntas 9 e 10. Fonte: Gerada pelo Google Forms a partir de questionário de elaboração própria, 2019

Para finalizar o questionário, foi perguntado se os entrevistados acreditam que a Área Calma poderia ser melhorada (Fig. 7), o que teve $85,8 \%$ das respostas favoráveis. Os principais pontos indicados para receber essas melhorias (Fig. 7), sendo a pergunta de múltipla escolha, foram a qualidade e acessibilidade das vias e calçadas $(76,8 \%)$, a sinalização $(72,3 \%)$, a infraestrutura e o mobiliário urbano $(59,8 \%)$ e as áreas verdes e os espaços públicos $(55,4 \%)$. Também houve a identificação de outras questões, como meios de transporte disponíveis, segurança no trânsito, fiscalização, ciclovias e vias compartilhadas, apontadas em menor quantidade. A partir dessas perguntas, foram constatadas algumas opiniões e impressões das pessoas a respeito da Área Calma, o que permitiu o entendimento da percepção de diferentes usuários sobre o assunto.

Você acha que a Área Calma poderia ser melhorada? 113 respostas

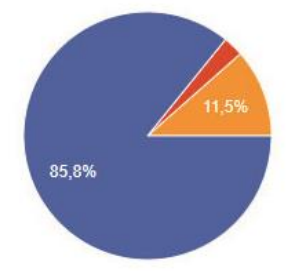

\section{Sim}

Talvez

Quais pontos poderiam receber melhorias?

112 respostas

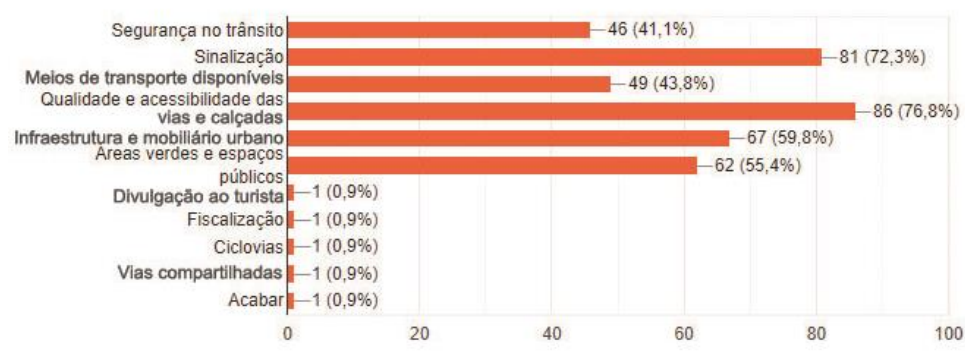

Fig. 7 - Resultado das perguntas 11 e 12. Fonte: Gerada pelo Google Forms a partir de questionário de elaboração própria, 2019 


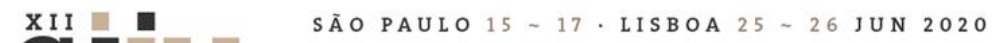

\subsection{Perfis de usuários}

Com as informações obtidas através da aplicação do questionário, foram criados perfis de usuário (Fig. 8) da Área Calma, estabelecidos a partir de questões relacionadas à utilização e ocupação dos espaços urbanos pelas pessoas. Essas questões são: a) o motivo de frequentar a área; b) se permanece por algum tempo ou se está de passagem; c) a frequência de uso; d) o modal utilizado para se deslocar até ela/dentro dela. Desse modo, foram gerados cinco perfis de usuários, com a intenção de determinar situações genéricas, mas que, ao mesmo tempo, fossem possíveis de existir. Esses tipos de usuários são: a) usuário permanente 1 - morador; b) usuário permanente 2 - trabalha/estuda; c) usuário frequente 1 - permanece; d) usuário frequente 2 - passagem; e) usuário ocasional - pouca frequência.

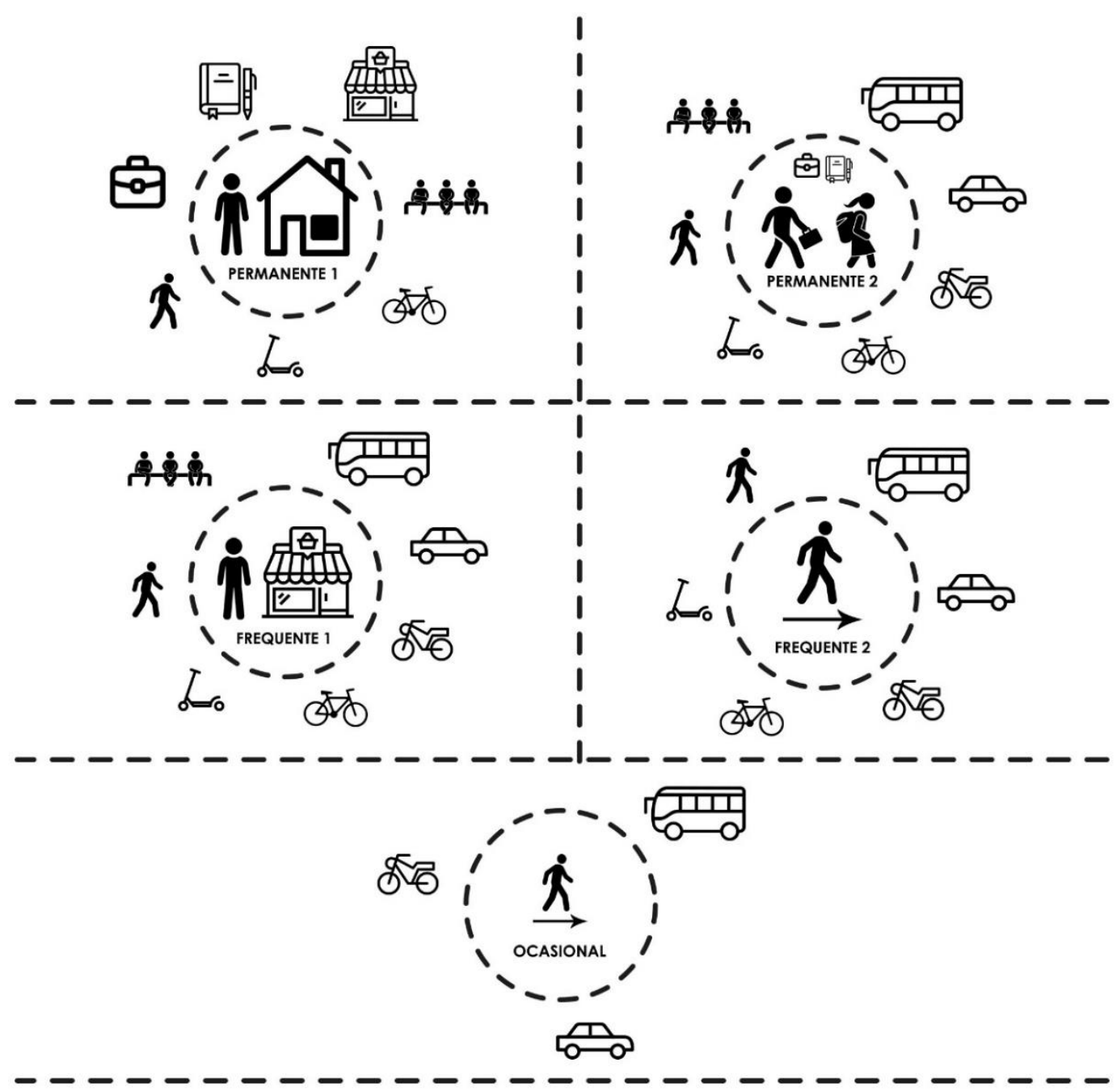

Fig. 8 - Diagramas dos perfis de usuário. Fonte: Elaboração própria, 2019. 


\section{SÃOPAULO15 $17 \cdot$ LISBOA $25 \sim 26$ JUN 2020}

\section{ESCALAS E ESTRATÉGIAS}

Buscando desenvolver as possíveis formas de atuação da proposta na área, foram definidas duas dimensões, sendo elas a do plano e a do projeto. Com isso, as estratégias de intervenção no local foram produzidas com base em quatro escalas. Essas são: a) escala municipal, que deve estar presente em todas as propostas e ligada a um plano municipal; b) escala de centro expandido, abrangendo a área central da cidade e o entorno; c) escala interna integrada, ligada ao espaço envolvido pela Área Calma; d) escala de microintervenção, que se relaciona a pontos específicos dentro do recorte.

Considerando as três últimas escalas, a cada uma foram associados os perfis de usuários - citados anteriormente -, de acordo com as possíveis relações estabelecidas entre usuário e escala. Isso demonstrou que, quanto maior é a aproximação com as escalas menores, chegando na microintervenção, mais se afeta os usuários permanentes, que são os que têm mais relação com o espaço e estão presentes de maneira predominante na região. Dessa forma, as escalas maiores provocam consequências para os usuários em geral, enquanto as menores geram impactos, principalmente, nos usuários permanentes.

A partir da síntese do levantamento já realizada, a área foi dividida em quatro partes, com características particulares, sendo que cada uma corresponde a uma estratégia de intervenção própria (Fig. 9). As estratégias das quatro áreas, identificadas pelo número, foram listadas a seguir: 1) renovar o espaço público através de microintervenções; 2) qualificar o Passeio Público e o entorno; 3) ativar a mobilidade e qualificar a permanência; 4) gerar uma transição entre as áreas 1 e 3 e valorizar o caráter histórico.

Essas estratégias se desenvolveram por meio da associação de diretrizes para cada uma, o que permitiu a definição de produtos. Assim, a diretriz que orientou a estratégia 1 foi a de gerar uso e movimentação, já a relativa à estratégia 2 foi tornar a área mais atrativa e adequada para pedestres. Em relação à estratégia 3 , a diretriz foi organizar e usufruir do alto fluxo e variedade de modais e, por último, a intenção da estratégia 4 foi a de criar uma identidade específica. Com base nessas questões, cada área apresentou um conjunto de produtos, que foram relacionados com as diferentes escalas de atuação (Fig. 10). Alguns desses produtos são a aplicação de instrumentos urbanísticos, a intervenção espacial, a criação de uma macroestratégia de deslocamento, entre outras ações. 


\section{SÃO PAULO15 17 LISBOA $25 \sim 26$ JUN 2020 \\ Seminário Internacional de Investigação em Urbanismo \\ Seminario Internacional de Investigación en Urbanismo}

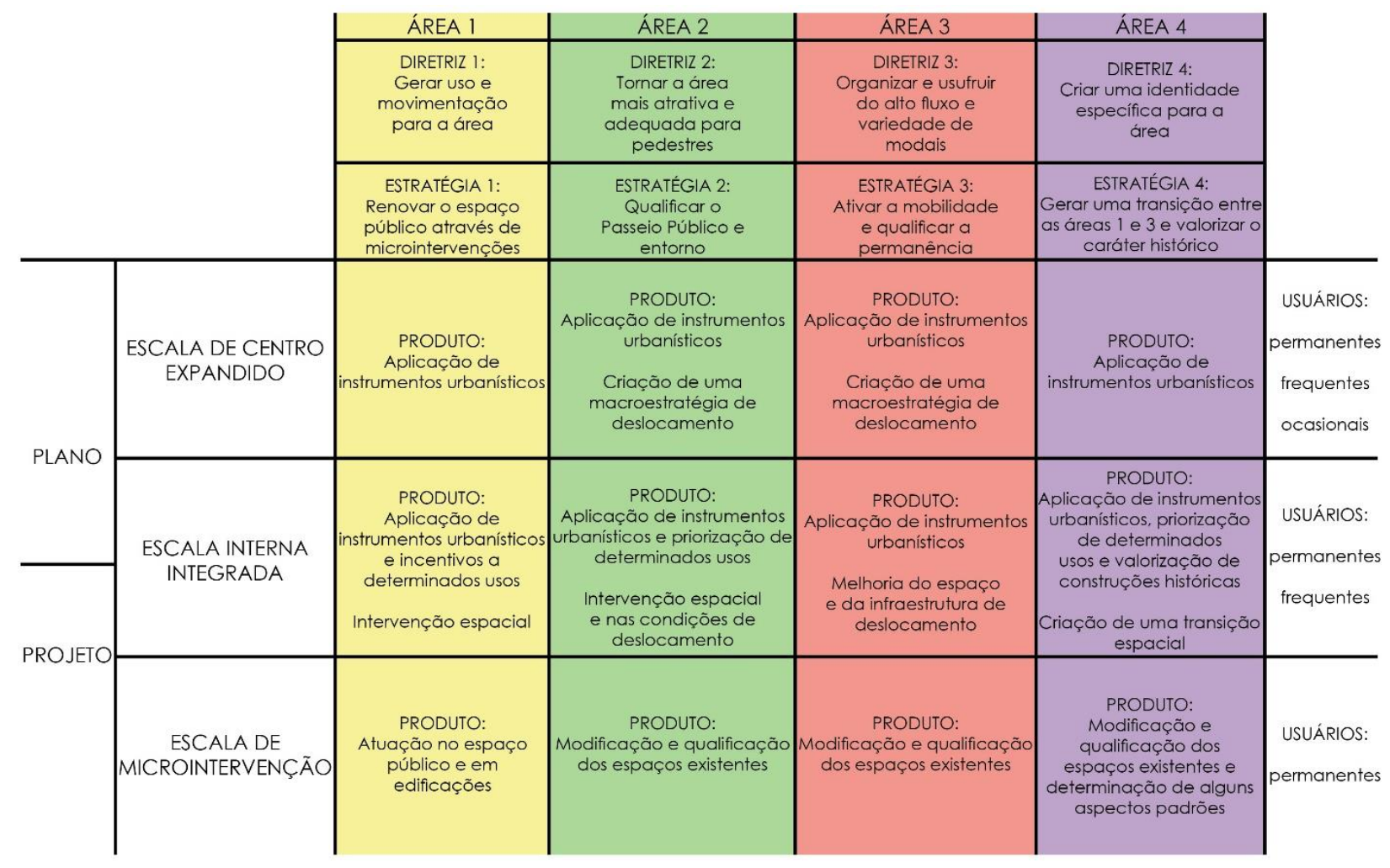

Fig. 10 - Tabela de associação entre dimensões, escalas, áreas e usuários. Fonte: Elaboração própria, 2019

\section{CENÁRIOS}

A partir do reconhecimento das escalas e da produção de estratégias, foram desenvolvidos quatro cenários, com o objetivo de identificar os problemas das diferentes áreas. Esses cenários são genéricos, ou seja, não apresentam lugares reais, mas representam as principais problemáticas encontradas em cada área. Além disso, os cenários correspondem, de acordo com o número de cada um, às respectivas estratégias das quatro áreas, explicadas anteriormente. Por meio dessas relações, são apontadas as possíveis propostas, realizadas nas dimensões de plano e de projeto, que podem responder a essas questões buscando solucionar os problemas existentes.

As problemáticas da área 1 são: a) falta de valorização das construções de esquina; b) muros, grades e fachadas cegas ou inativas; c) desenho urbano fragmentado e pouco uso do espaço público; d) uso predominantemente residencial e poucos comércios e serviços. Já as propostas apresentadas pelo cenário 1 (Fig. 11) são: a) priorização das construções de esquina, ligando-as ao espaço público; b) aplicação do instrumento urbanístico de Fachada Ativa, impedindo ou limitando muros, grades e fachadas cegas; c) transformação dos espaços ociosos por meio do desenho urbano; d) incentivos a usos comercial e de serviços, associados ao uso residencial existente. 


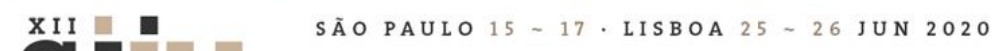

Seminário Internacional de Investigação em Urbanismo

Seminario Internacional de Investigación en Urbanismo

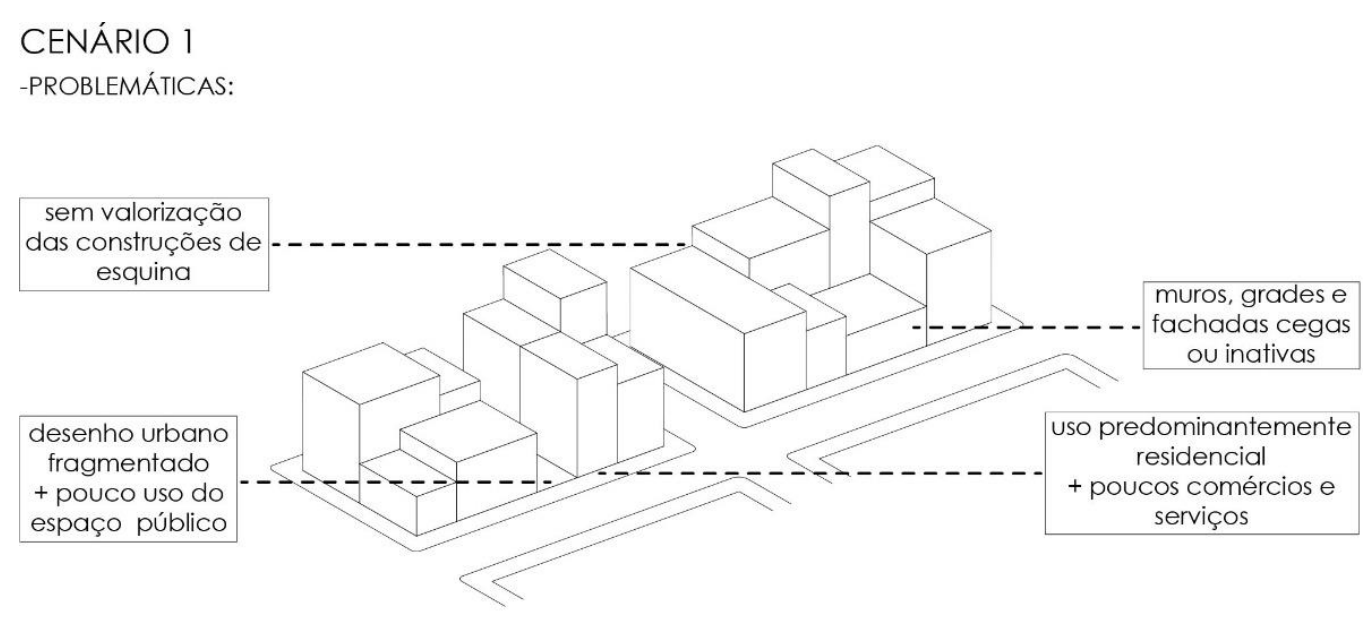

-PROPOSTAS:

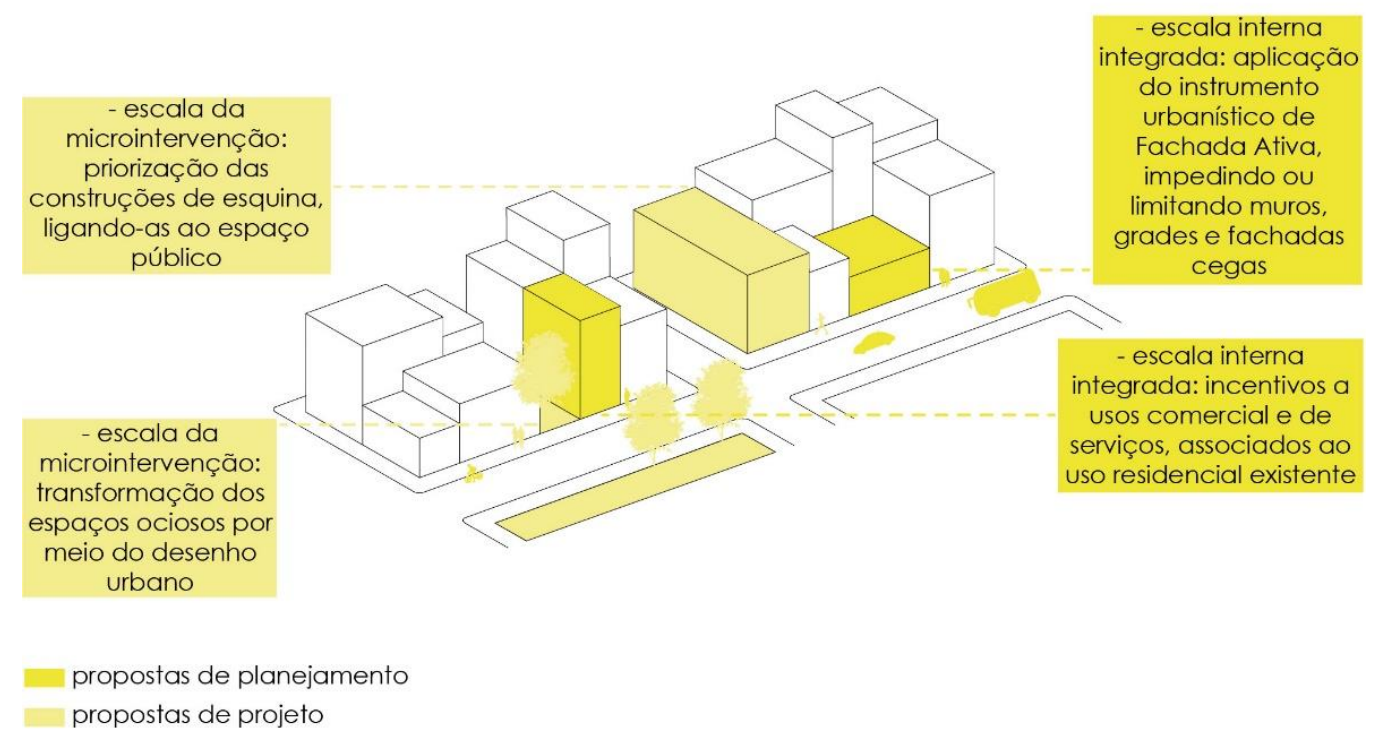

Fig. 11 - Diagrama do cenário 1. Fonte: Elaboração própria, 2019.

A área 2 tem como problemáticas: a) dificuldades de deslocamento, pouca atratividade de pedestres e pouco uso do espaço público; b) lotes subutilizados, abandonados ou com estacionamentos; c) priorização de veículos individuais e ônibus. Enquanto as propostas do cenário 2 (Fig. 12) incluem: a) aumento do espaço destinado a pedestres, qualificação dos espaços públicos existentes e criação de novos; b) geração de novos usos em lotes ociosos através dos instrumentos de PEUC (Parcelamento, Edificação ou Utilização Compulsórios), IPTU Progressivo no Tempo e Desapropriação com Pagamento em Títulos, além da priorização de habitação e equipamentos públicos; c) criação de uma macroestratégia de deslocamento para veículos individuais e ônibus, limitando o acesso de veículos individuais. 


\section{SÃOPAULO15 $17 \cdot$ LISBOA $25 \sim 26$ JUN 2020}

Seminário Internacional de Investigação em Urbanismo

Seminario Internacional de Investigación en Urbanismo

\section{CENÁRIO 2}

-PROBLEMÁTICAS:

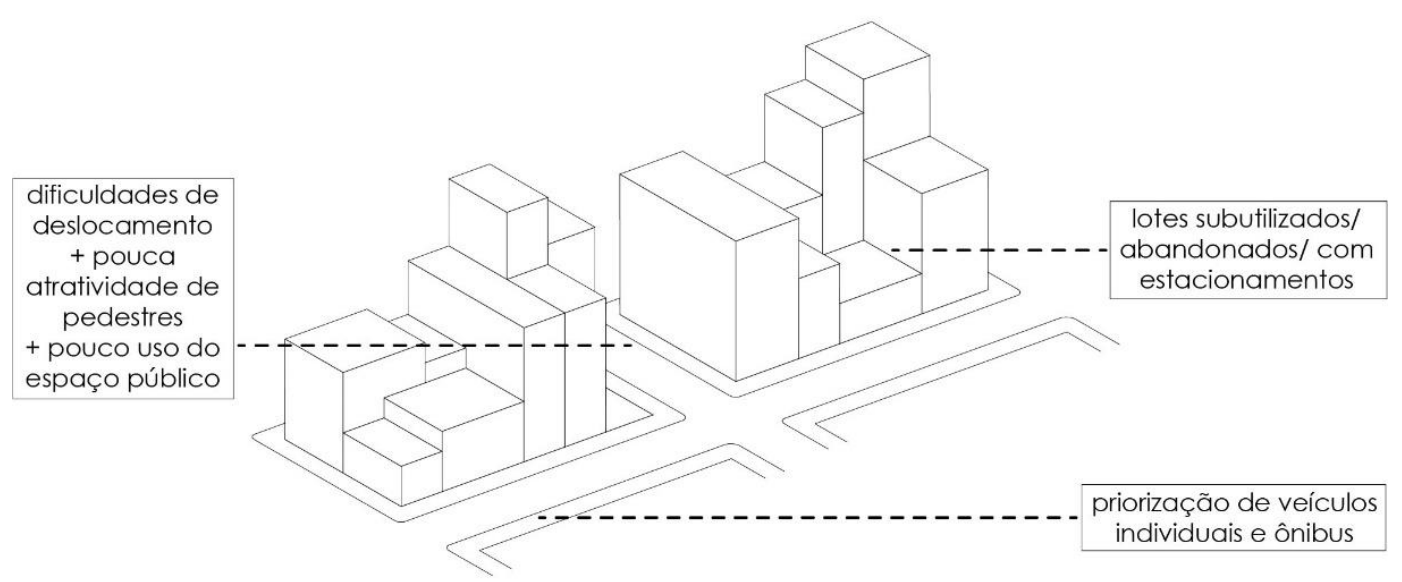

-PROPOSTAS:

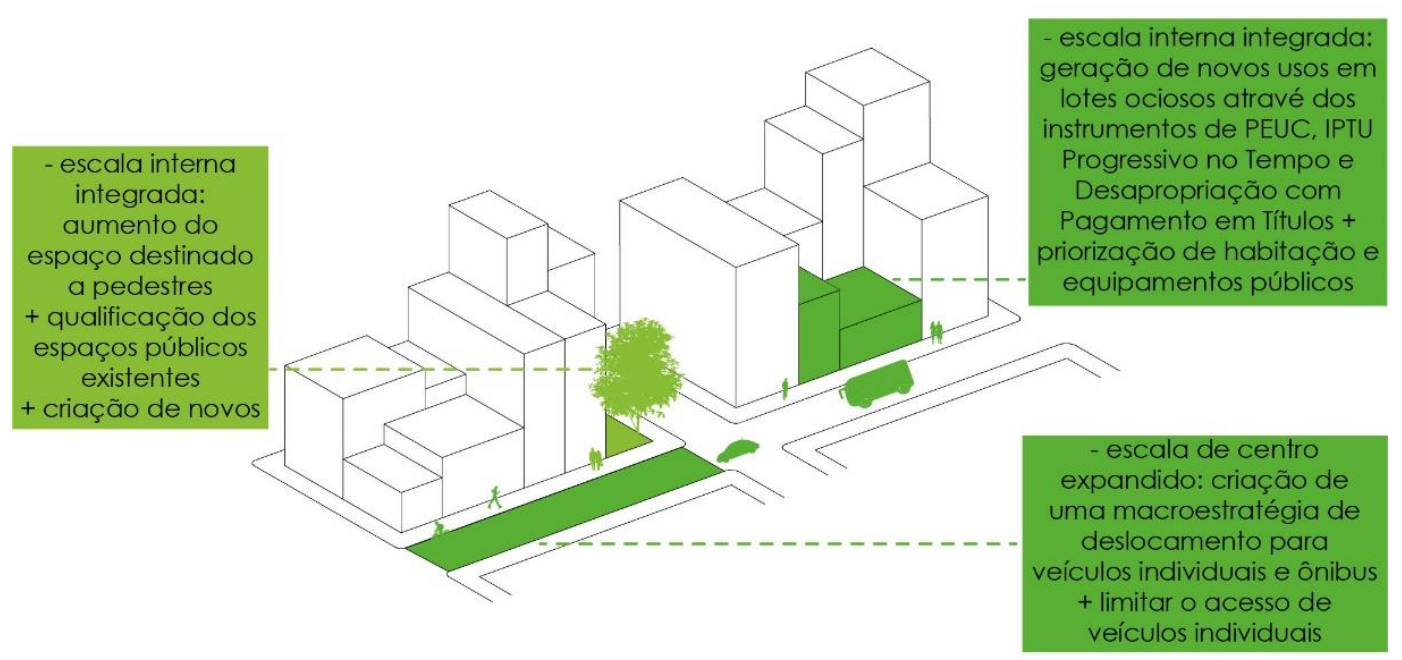

propostas de planejamento

propostas de projeto

Fig. 12 - Diagramas do cenário 2. Fonte: Elaboração própria, 2019.

Já a área 3 tem as seguintes problemáticas: a) falta de valorização do espaço público, muitas vezes usado com a função de atender ao transporte coletivo; b) pouca presença de habitação, em regiões com grande oferta de comércio, serviços e equipamentos públicos; c) priorização do deslocamento de veículos individuais e ônibus; d) dificuldades no deslocamento de pedestres e modais ativos, pela falta de espaço e de infraestrutura. Como propostas, o cenário 3 (Fig. 13) aponta: a) qualificação dos espaços públicos existentes como locais de permanência e criação de novos; b) criação de Habitação de Interesse Social em imóveis abandonados e em terrenos vazios ou subutilizados; c) criação de uma macroestratégia de deslocamento para veículos individuais e ônibus, limitando o acesso de veículos individuais; d) aumento do espaço e da 


\section{SÃOPAULO15 $\quad 17 \cdot$ LISBOA $25 \sim 26$ JUN 2020 \\ Seminário Internacional de \\ Seminario Internacional de Investigação em Urbanismo Investigación en Urbanismo}

infraestrutura para pedestres e modais ativos, além da criação de áreas exclusivas para pedestres e modais ativos.

\section{CENÁRIO 3}

-PROBLEMÁTICAS:

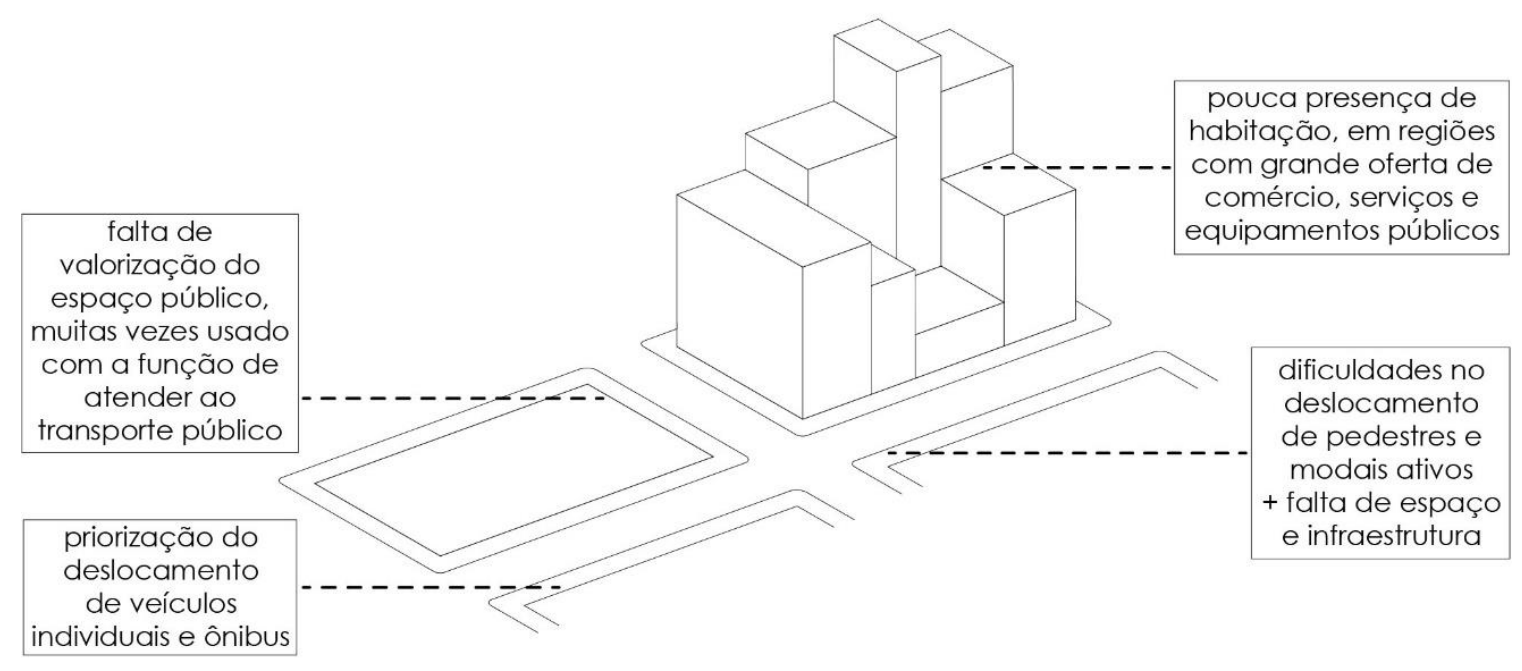

-PROPOSTAS:

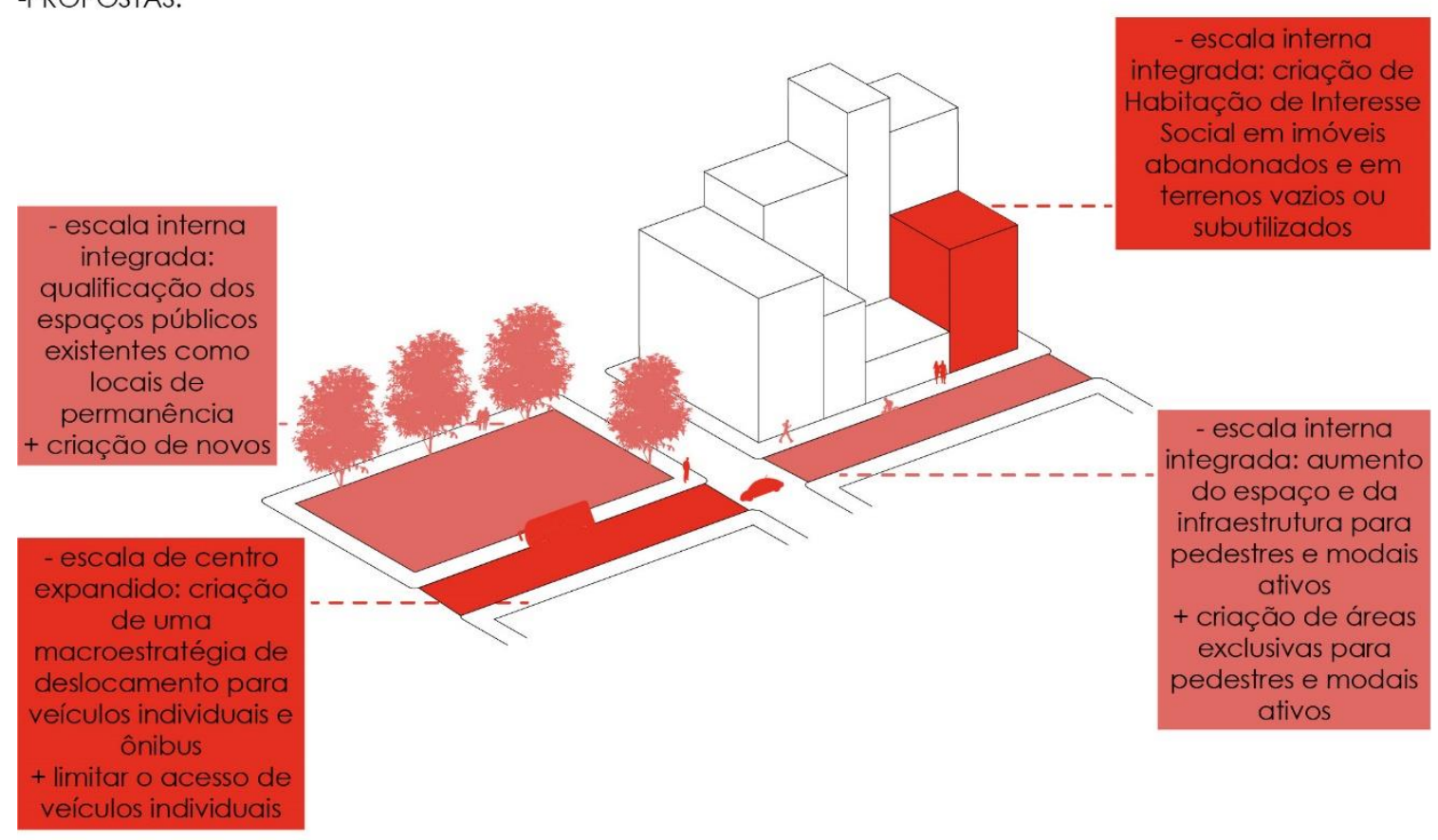

propostas de planejamento

propostas de projeto

Fig. 13 - Diagrama do cenário 3. Fonte: Elaboração própria, 2019. 


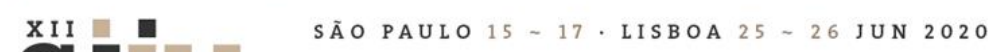

Seminário Internacional de Investigação em Urbanismo
Seminario Internacional de Investigación en Urbanismo

Por último, as problemáticas da área 4 são: a) falta de definição em relação a alturas, concentração de edifícios e movimentação de pessoas; b) existência de lotes vazios, subutilizados, com construções abandonadas ou com estacionamentos; c) falta de valorização de locais e construções históricas; d) espaços que sobram no desenho da cidade, vazios ou sem uso. E as propostas definidas pelo cenário 4 (Fig. 14) são: a) criação de uma transição espacial e funcional entre as áreas 1 e 3, por meio da adoção de usos, concentração e altura de edifícios variáveis, criando aspectos intermediários em relação às duas áreas; b) geração de novos usos em lotes vazios, subutilizados ou com construções abandonadas através dos instrumentos de PEUC (Parcelamento, Edificação ou Utilização Compulsórios), IPTU Progressivo no Tempo e Desapropriação com Pagamento em Títulos, além da priorização de habitação e equipamentos públicos; c) valorização e geração de novos usos para locais e construções históricas, com o estabelecimento de benefícios através da Transferência do Direito de Construir; d) transformação dos espaços ociosos por meio do desenho urbano.
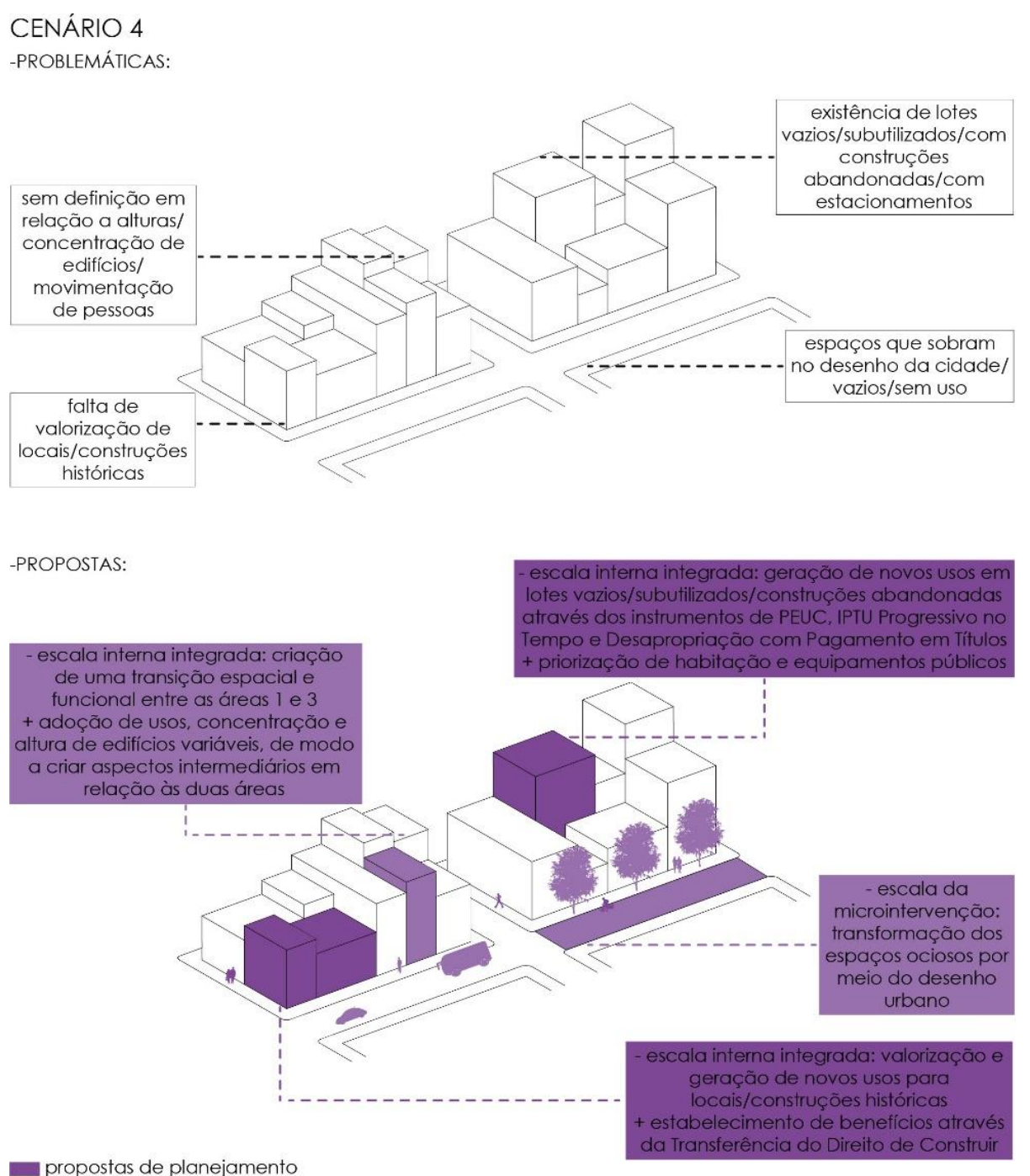

propostas de planejamento propostas de projeto

Fig. 14 - Diagrama do cenário 4. Fonte: Elaboração própria, 2019. 


\section{SÃOPAULO15 $17 \cdot$ LISBOA $25 \sim 26$ JUN 2020}

\section{CONCLUSÃO}

Considerando todo o processo apresentado neste artigo e o estudo realizado em relação ao recorte escolhido, tornou-se claro que a Área Calma apresenta problemas desde a concepção do projeto, incluindo a falta de interesse que se teve em, realmente, planejar e desenvolver uma visão para criar essa área, até a implantação na realidade. Além disso, não cumpre de forma completa os objetivos apontados pelo Decreto de Implantação da Área Calma, demonstrando uma diferença entre o que se pretendia realizar e o que, realmente, ocorreu na prática. Essas questões comprometem tanto o funcionamento da região, por ter sido comprovado que essa foi mal estruturada, quanto o entendimento que as pessoas têm a respeito dela, pelo fato de se revelar como ineficiente e confusa.

Também houve uma preocupação em indicar que boa parte dos motivos que fazem o local manifestar dificuldades está ligada a uma falta de atenção para o espaço físico, deixando de lado a importância do Desenho Urbano. Esse foi exposto pelo texto como um campo disciplinar que, apesar de relativamente novo se comparado a outros, está consolidado e é fundamental para a análise da vida urbana, o reconhecimento de problemas e a atuação no espaço de forma coerente. Assim, nota-se a necessidade do Desenho Urbano para o desenvolvimento das cidades, ao envolver diversas questões, constituir uma grande complexidade e tratar de uma escala mais específica, muitas vezes não considerada por outros campos (Olivieri, 2019).

A respeito das investigações sobre a área, o levantamento, ao abranger vários aspectos espaciais e dinâmicos, permitiu o entendimento de características representativas da região e a identificação de partes específicas, que estabeleceram diferentes relações entre si, gerando a divisão apresentada no artigo. A aplicação do questionário possibilitou uma aproximação com o pensamento de quem utiliza a área, evidenciando opiniões sobre diversos problemas pelo ponto de vista dos entrevistados, o que amplia a assimilação do contexto geral. A última parte da análise foi a criação dos perfis de usuário, definidos por meio de informações reais e situações possíveis, que ajudaram ainda mais a incorporar a perspectiva da população no estudo do local.

Já em relação às estratégias, produzidas com base nas escalas e associadas aos perfis de usuário, houve uma sistematização das problemáticas para determinar o objetivo principal de intervenção em cada uma das quatro áreas demarcadas. Isso proporcionou uma simplificação das questões envolvidas nos processos de avaliação dessas regiões, o que resultou nos quatro cenários finais. Esses foram retratados como recomendações sobre o que poderia ser aplicado na Área Calma, tendo em vista os problemas observados, com a intenção de modificar a estrutura atual, promover um bom funcionamento e qualificar a vivência urbana.

\section{BIBLIOGRAFIA}

\subsection{Obra completa}

DEL RIO, V. (1990). Introdução ao desenho urbano no processo de planejamento. São Paulo: Pini.

HALL, P. (2005). Cidades do amanhã: uma história intelectual do planejamento e do projeto urbanos no século XX. São Paulo: Perspectiva. 


\section{XII}

INSTITUTO DE PESQUISA E PLANEJAMENTO URBANO DE CURITIBA (IPPUC) (2014). Área Calma Estudo de Viabilidade. Curitiba: IPPUC.

LAMAS, J. M. R. S. (1993). Morfologia urbana e desenho da cidade. Lisboa: Fundação Calouste Gulbenkian.

OLIVIERI, A. A. (2019). Desenho Urbano como estruturador da Área Calma na região central de Curitiba.

\subsection{Leis ou Decretos}

CURITIBA (2015a). Decreto ํㅜ 871/2015, de 17 de setembro de 2015. Dispõe sobre a implantação da Área Calma, no âmbito do Município de Curitiba. Diário Oficial do Município de Curitiba, Curitiba, PR.

\subsection{Fontes eletrônicas}

CURITIBA. (2016). Prefeitura Municipal. Área Calma completa um ano com redução de acidentes e multas. Curitiba. Disponível em: <http://www.curitiba.pr.gov.br/noticias/area-calma-completa-um-ano-com-reducaode-acidentes-e-multas/40574>. Acesso em: 20 jan. 2020.

(2015b). Conheça melhor a região da Área Calma. Curitiba. Disponível em: <http://www.curitiba.pr.gov.br/noticias/conheca-melhor-a-regiao-da-area-calma/37604>. Acesso em: 20 jan. 2020. 